\title{
Prevalence of aflatoxin in dried okra (Abelmoschus esculentus) and tomatoes (Lycoperisicon esculentum) commercialized in Ibadan metropolis
}

\author{
Okigbo RN* and Anene CM \\ Botany Department, Nnamdi Azikiwe University Awka, P.M.B 5025, Awka Anambra State, Nigeria
}

\section{Introduction}

Aflatoxin as defined by Busby and Wogan [1] are group of carcinogenic, tetragenic and mutagenic mycotoxins commonly associated with fruits, vegetables and other products whilemycotoxins generally aresaid to be poisonous secondary metabolites produced by moulds when growing on different food products [2].

In West African sub-regions, aflatoxin B1, B2, G1 and G2 are the major ones because they are thermo-stable [3] and due to their high prevalence in nature and toxicity are said to be the most important mycotoxins in food and feeds [4].

Historically, scientific research on Aflatoxin started after the incidence that took place the year 1960 in England where a large number of turkey poults died after eating contaminated groundnut meal that was imported from Brazil, the atoxigenic fungus was identified as Aspergillus flavus and the toxic principle named Aflatoxin meaning Aspergillus toxin [5].

The significance of this study is to give insight on the causes of aflatoxicosis outbreak in Ibadan city. It also provides adequate information on the level of aflatoxins in the vegetables as they form a vital nutritious component of the daily diet of the citizens. It will also be vital in setting up prevention, control and management programs on aflatoxin contamination in Ibadan as a public health issues.

Aflatoxin contamination of food is said by Bhat and Miller [6] to be of serious problem as they bind to DNA and consequently prevent transcription of genetic information which eventually has an adverse effect in humans and other animals. More so, they have been reported by Stoloff [7] to be acutely and chronically toxic causing acute Liver damage, Liver cirrhosis, induction of tumors and teratogenic effects.

Report on the various infestations of Okra and tomatoes by Aspergillus species [4] and the ability of some Aspergillus strains to produce aflatoxin [8] justifies the need to determine the possible contamination of these vegetables with aflatoxin. The aim of this research work is to provide information on the natural occurrence of aflatoxin in the two vegetables sold in Ibadan metropolis in lieu of the very scarce data on it.

The objective of the study is to determine;

The incidence and concentration of aflatoxins in these commodities and The occurrence of the fungi on the them

\section{Materials and methods}

\section{Sterilization of materials used for the research}

All materials used for the research work were sterilized and the media was prepared according to manufacturer's instruction and autoclave at $121^{\circ} \mathrm{C}$ for 10 minutes [9-11].

\section{Samples collection}

Hundred grams of each sample were collected from the four markets namely Oje, Bodiga, Shasha and Orita-merin in five replicate of 20 gram in separate airtight sterile polythene bag to prevent further contamination until aflatoxin analysis was done and subsequent isolation and identification of fungi.

\section{Aflatoxins Extraction}

Aflatoxins was extracted from the samples as described by Hell, et al. [12] with modifications employed due to different weight and dryness of the samples. Dichloromethan was used to extract the toxin and allowed to evaporate to dryness in laminar air flow-hood chamber for 48 hours until analysed.

\section{Qualitative analysis}

Four micro litres of the dissolved extract were spotted on the thin layer chromatography (TLC) plates $20^{\star} 10 \mathrm{~cm}$ with aflatoxin standards $\mathrm{G}$ and $\mathrm{I}$ and then allowed to develop in a tank containing diethyl ether, methanol and water at the ratio of 96: 3: 1 respectively. The spots intensities were visually compared with those of standards under ultraviolet light $366 \mathrm{~nm}$ wavelengths [13].

\section{Quantitative analysis}

Aflatoxin quantification was done by scanning with CAMAG TLC Scanner3 (densitometer), which measured the absorbance and fluorescence of the toxin extracted [14].

\section{Isolation of fungi}

Direct isolation method was employed for fungi isolation. The samples were surface sterilized in $70 \%$ ethanol for 10 minutes and

Correspondence to: Okigbo RN, Botany Department, Nnamdi Azikiwe University Awka, P.M.B 5025, Awka Anambra State, Nigeria, Tel: 2348052239358; E-mail: okigborn17@yahoo.com

Received: November 26, 2017; Accepted: December 28, 2017; Published: January 02, 2018 
rinsed in three changes of sterile distilled water and dried on a sterile filter paper [15]. Five pieces of each sample were directly inoculated on Petri-dishes containing Sabouraud Dextrose Agar (SDA) in 5 replicates and sealed with paraffin to prevent contamination. The plates were then incubated at $27^{\circ} \mathrm{C}$ for 5 days and then sub cultured to obtain pure culture of the isolates

\section{Identification of fungi}

Isolates were identified based on colony characteristics, strain morphology, macroscopic feature and microscopic feature [16]. The pure cultures were characterized and subsequently identified with the aid of a compound microscope as the representatives of the different colonies/fungi [16].

\section{Statistical analysis}

The experimental design was a complete randomized one. The levels of aflatoxin contamination on the samples were illustrated with an error bar chart at $95 \% \mathrm{cl}$. The chart was obtained by plotting the aflatoxin concentrations against the different markets. The incidences of the fungi were determined by calculating their percentage frequency. IBM SPSS Statistical data editor version 21.00 was used to perform the ANOVA and chi-square analysis at $\mathrm{P}<0.05$ level of significance.

\section{Percentage occurrence of fungi}

Calculation of the percentage occurrence of the different fungi isolates were done to determine their frequencies from the 4 different markets. Five plates from each market were used, the number of occurrence of each of the isolates was recorded, the mean taken and calculated as a ratio of the total number of occurrence and then expressed as a percentage using the formula:

\section{Percentage occurrence $=\mathrm{X}$}

$\mathrm{X}=$ Total number of each isolate in all the market samples

$\mathrm{N}=$ Total number of all isolates in all the market samples

\section{Mean}

$\mathrm{EX}=$ summation of all the isolates from the 5 plates of a market sample

$\mathrm{N}=$ Number of all isolates in the 5 plates of a market sample

\section{Results}

\section{Aflatoxins ( $p p b)$ content of driedokra and tomato sampled from four markets in Ibandan}

The aflatoxin content (ppb) in dried okra sampled from four markets in Ibandan is shown in Figure 1. The figure revealed that aflatoxin B1 was highest in samples from Oje market (33.490ppb) and lowest in samples from Bodija market (26.690ppb). Aflatoxin B2 was highest in samples from Bodija market (3.736) and lowest in samples from Oje (0.70ppb). Aflatoxin G1 was highest in sample from Oje market (22.583ppb) and lowest in samples from Bodija market (1.360ppb). Aflatoxin G2 was highest in samples from Oretamierin market (2.254ppb) and lowest in samples from Bordija market $(1.360 \mathrm{ppb})$. There was significant difference in the content of aflatoxin in okra samples between the various markets $(\mathrm{p}<0.05)$.

The aflatoxin content (ppb) in dried tomatoes sampled from four markets in Ibandan was shown in Figure 2. The figure revealed that all the aflatoxin assayed is absent in dried tomato from Bodija market. However, for other markets, aflatoxin B1 was highest in samples from Oritamerin market (1.43ppb) and lowest in samples from Oje market

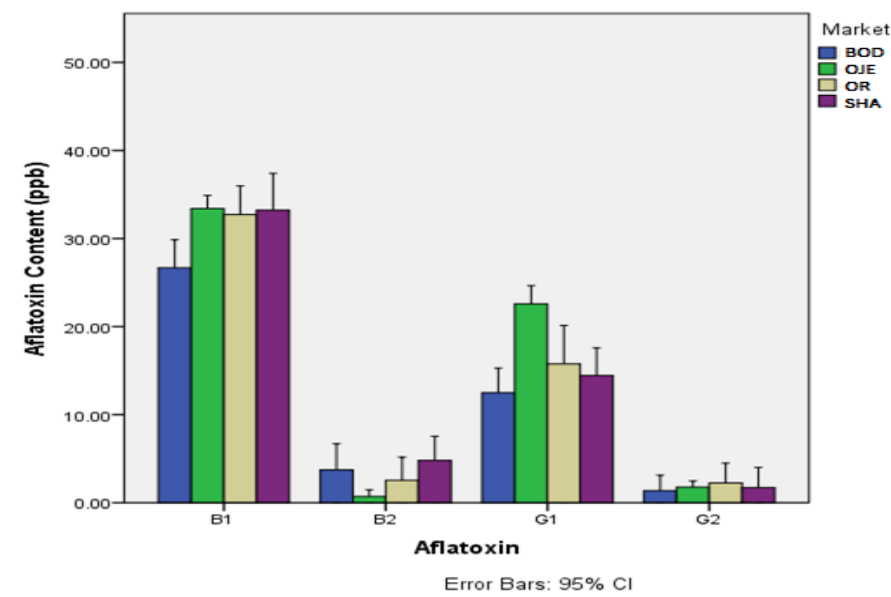

Figure 1. Aflatoxin content (ppb) in dried okra sampled from four markets in Ibandan BOD: Bordija Market; OJE: Oje Market; OR: Oritamerin Market; SHA: Shasha Market

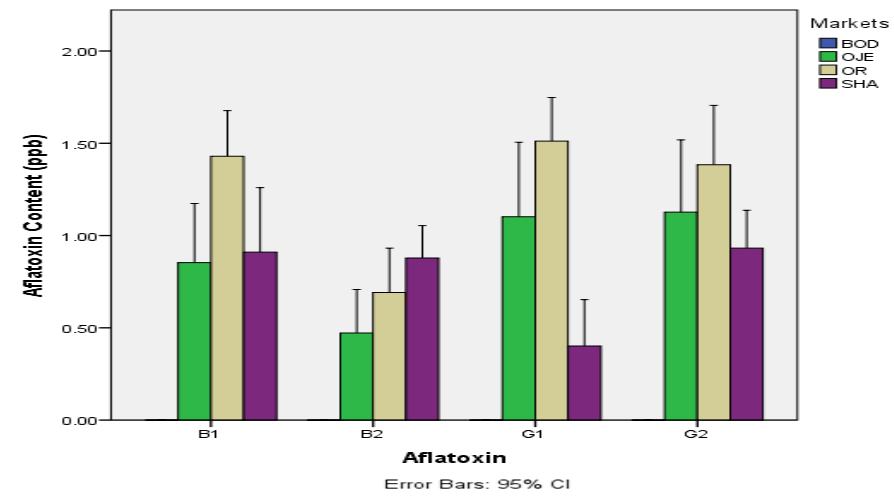

Figure 2. Aflatoxin content (ppb) in dried tomato sampled from four markets in Ibandan BOD: Bordija Market; OJE: Oje Market; OR: Oritamerin Market; SHA: Shasha Market

(0.853ppb). Aflatoxin B2 is highest in samples from Shasha market $(0.878 \mathrm{ppb})$ and lowest in samples from Oje $(0.472 \mathrm{ppb})$. Aflatoxin G1 was highest in samples from Oritamerin market (1.512ppb) and lowest in samples from Shasha (0.402ppb). Aflatoxin G2 was highest in samples from Orita-merin market (1.383ppb) and lowest in samples from Shasha market $(0.932 \mathrm{ppb})$. There was significant difference in the content of aflatoxin in dried tomato seeds between the various markets $(\mathrm{p}<0.05)$

\section{Percentage occurrence of aflotoxin producing fungi in okra and tomato sampled from various markets in Ibadan}

The percentage occurrence of aflatoxin producing fungi in dried Okra sampled from four markets in Ibadan is shown in Table 1. A total of three aflatoxin producing fungi include A. flavus, A. niger and $A$. parasiticus were isolated from dried okra seed samples from the four markets. A. flavus reported the highest occurrence in Bodija market (100\%) and Oje market (100\%). A. nigerrecorded the highest occurrence in Oritamerin market $(60 \%)$ and Shashs market (60\%) while A. parasiticus showed the highest occurrence in Oje market (80\%) and Shasha market $(80 \%)$. In all the markets, the percentage occurrence of A. flavus was the highest (95\%) while that of A. Niger was the least (50\%). The aflotoxinproducing fungi showed a significant difference in their percentage occurrence between the markets $(\mathrm{p}<0.05)$.

The percentage occurence of aflatoxin producing fungi in dried tomatoes sampled from four markets in Ibadan is shown in Table 2. 
Table 1. Percentage occurence of fungal isolates in dried okra sampled from four markets in Ibadan

\begin{tabular}{|c|c|c|c|c|c|}
\hline \multirow{2}{*}{$\begin{array}{c}\text { Aflatoxin producing } \\
\text { fungi }\end{array}$} & \multicolumn{5}{|c|}{ Markets (\% Occurence) } \\
\cline { 2 - 6 } & Bordija & Oje & Oritamerin & Shasha & Total \\
\hline A. flavus & 100 & 100 & 80 & 100 & 95 \\
\hline A. niger & 40 & 40 & 60 & 60 & 50 \\
\hline A. parasiticus & 60 & 80 & 60 & 80 & 70 \\
\hline
\end{tabular}

$\chi^{2}=18.666, \mathrm{p}=0.045$

Table 2. Percentage occurence of fungal isolates in dried tomato sampled from four markets in Ibadan

\begin{tabular}{|c|c|c|c|c|c|}
\hline \multirow{2}{*}{$\begin{array}{c}\text { Aflotoxin producing } \\
\text { fungi }\end{array}$} & \multicolumn{5}{|c|}{ Markets (\% Occurence) } \\
\cline { 2 - 6 } & Bordija & Oje & Oritameri & Shasha & Total \\
\hline A. flavus & 20 & 80 & 40 & 20 & 40 \\
\hline A. niger & 20 & 20 & 40 & 20 & 25 \\
\hline A. parasiticus & 20 & 20 & 60 & 60 & 45 \\
\hline
\end{tabular}

$x^{2}=111.67, \mathrm{p}=0.000$

A total of three aflotoxin producing fungi include A. flavus, A. niger and $A$. parasiticus were isolated from dried tomato seed samples from the four markets. A. flavus reported the highest occurrence in Oje market (80\%). A. niger recorded the highest occurrence in Oritamerin market (40\%) while A. parasiticus showed the highest occurrence in Oritamerin and Shasha markets (60\%). In all the markets, the percentage occurrence of $A$. parasiticuswas the highest (35\%) while that of A. flavus was the least (25\%). The aflotoxin producing fungi showed a significant difference in their percentage occurrence between the markets $(\mathrm{p}<0.05)$.

\section{Discusion}

The level of aflatoxin B1 was higher in okra sample when compared to aflatoxins G1, G2 and B2. High prevelences of this aflatoxins may be due to the high percentage occurrence of $A$ flavus and A parasiticus in the sample. This lends support to the work of Segun et al. [17] who showed aflatoxin B1 to be higher in stored orunla samples from the different market in Ibadan Nigeria when compared with other toxins due to the high percentage occurrence of A.flavus. It also support to the study of Ayalen 2006, who showed aflatoxin B1 to be the most abundant and most toxic followed G1.

In dry tomatoes samples, the distribution of aflatoxin B1, G1 and G2 were alike while B2 was the lowest . this also may be related to high percentage occurrence of A flavus and A parasiticus. This result lends support to the study of Muhammad, et al. [18] that detected aflatoxin in rotton tomatoes from 5 local markets in Nigeria even after treatment at $121 \mathrm{c}$ for 15 minutes. This gives an insight on the persistence of aflatoxins even after high temperature treatment during processing.

In comparison, the aflatoxin content in okra samples were higher than in tomatoe samples. This may be due to another important aspect of the mycotoxin production in foodstuff which is based on the presence or absence of compounds that inhibit the toxin synthesis as tomatoes contain polyphenols which might suppress the synthesis of such toxin [19]. The detection of aflatoxin in these samples might also be attributed to poor agronomic practices, harvesting method, handling, processing, storage and market sanitations this is in line with the work of Ayalen, and Okigbo, et al. [20,21].

Three fungi pathogens including; A. flavus, A. niger and A. paristicus were associated with production of aflatoxins in the dry okra and tomatoesamples. This result lends support to the findings of Atehnenkeng. et al. [22], Segun, et al. [17] and Hell, et al. [12] that $A$. flavus and A. Parasiticus are major aflatoxins producing fungi which contamination many food commodities
The percentage occurence of $A$. flavus was highest in okra samples while that of $A$. parasticus was highest in tomatoe samples. This difference in the occurence of the fungi pathogens in the food products has been attributed to differences in nutrient conditions and differences in biaactive compounds in the plants [20].

Finally, the result of the study also indicated the percentage occurence of aflatoxin producing fungi to differer between markets. Thus, might be due to the market sanitation and handling by the sellers. Okigbo, et al. [21] has also emphasised that factors such as harvesting method, handling, processing, storage and even climate can influence the presence and abundance of aflatoxins producing fungi in food products.

\section{Conclusions and recommendation}

Hazard analysis critical control point (HACCP) should be adopted at every point during food processing chain to help reduce fungi infection and subsequent aflatoxin contamination of food commodities.

Government should also enforce enlightenment programs to educate the citizens about food safety. Also, Mycotoxin regulations should be adopted in our country to help regulate the level of mycotoxin in locally consumed food to ensure food security which is basic for good health and better economy. There is also a need for further research on how best to prevent and control these toxins.

\section{References}

1. Busby Jr WF, Wogan GN (1981) Aflatoxins. In: Shank, R. C. (Ed.). Mycotoxins and N-nitroso Compounds: Environmental Risks. European University Association: CRC Press. London, pp: 3-28.

2. Zain F (2010) Impact of mycotoxins in human and animal. Journal of Saudi Chemical Society 15: 129-144

3. Marasas WFO, Nelson PE (1987) Mycotoxicology E.U.A.: The Pennsylvania State University Press, pp: 550

4. Makun HA, Dutton MF, Njobeh PB, Gbodi TA, Ogbadu GH (2012) Aflatoxin contamination in foods and feeds: A special focus on Africa. In: Prof. Ayman A.E. (Ed.) Trends in Vital Food and Control Engineering. In Tech, pp: 299.

5. Blount WP (1961) Turkey ' $X$ ' disease. Journal of British Turkey Federation 9: 52-57

6. Bhat RV, Miller JD (2010) Mycotoxins and Food Supply. Food Agriculture Organization corporateddocument repository. Accessed on 18th June 2016. http://www.fao.org docrep/ u3550t/u355ot0e.htm

7. Stoloff L (1977) Aflatoxins - an overview. In: Rodricks JV, Heseltine CW, Mehlman MA (Eds). Mycotoxins in Human and Animal Health. Park Forest South, IL: Pathotox, pp: 7-28.

8. Youssef MS, Abo-Dahab NF, abou-Seidah, A.A (2008). Mycoita and mycotoxins contamination of dried raisin in Egypt. African Journal of Mycology and Biotechnology 8: 69-86

9. Postagate J (1992) Microbes and Man. 3rd edition. Cambridge university press, USA, pp: 906.

10. Cheesebrought M (2000) Medical Lab Manual for Tropical Countries Microbiology Linzcre house, Jordan Hill, Oxford, pp: 260.

11. Jawetz MA, Brook GF, Butel JS, Morse SA (2004) Medical Microbiology. 23rd edition. McGraw Hill companies, Inc. Singapore, pp: 818.

12. Hell K, Gnonlonfin BGJ, Kodjogbe G, Lamboni Y, Abdourhamane IK (2009) Mycoflora and occurrence of aflatoxin in dried vegetables in Benin, Mali and Togo, West Africa International Journal of Food Microbiology 135: 99-104.

13. Soares LM, Rodrigues-Amaya D (1989) Survey of aflatoxins, ochratoxin A zearelenone and sterigmatocystin in some Brazilian foods. Utilizing a multi-toxin thin layer chromatographic method. Journal of Association of official Analytical Chemists 72: $22-26$.

14. Abolude FO, Ojediran VA (2006) Development and Quality Evaluation of Fortified "Amala". Anti-Counterfeiting Trade Agreement Sclentianum Polonorum Technology Alimentaria 5: 127-134. 
Okigbo RN (2017) Prevalence of aflatoxin in dried okra (Abelmoschus esculentus) and tomatoes (Lycoperisicon esculentum) commercialized in Ibadan metropolis

15. Ritchie B (1991) Practical Technique in Plant Pathology. CAB Waling ford. UK, pp: 102.

16. Mutegi CK, Ngugi HK, Hendriks SL, Jones RB (2009) Prevalence and factors associated with aflatoxin contamination of peanuts from Western Kenya. International Journal of Food Microbiology 130: 27-34.

17. Segun GI, Michael DA, Oluwatoyin AA, Odunayo JO, Ayandiran DA (2016) Food value, fungi and aflatoxin detection in stored Ounla (Abelmoschus esculentus L. Moench) from Ibadan. Researcher 8: 7-16

18. Muhammad S, Shehu K, Amusa NA (2004) Survey of the market diseases and aflatoxin contamination of tomato (Lycopersicon esculentum MILL) fruits in Sokoto, northwestern Nigeria. Nutrition and Food Science 34: 72-76.
19. Martinez-Valverde I, Periag J, Provan G, Chesson A (2002) Phenolic compounds, lycopene and antioxidant activity in commercial varieties of tomatoes (lycoperiscon esculentum). Journal of the Science of Food and Agriculture 82: 323-330.

20. Ayalen A, Fehrmann H, Lepschy J, Beck R, Abate D (2006) Natural occurrence of mycotoxins in staple cereals from Ethiopia. Mycopathologia 162: 57-63

21. Okigbo RN, Anukwuorji CA, Okafor CO (2015) Assessment of mycotoxins occurrence in Manihot esculenta, Irvinga gabonensis, Citrulllus colocynthes in Awka, Anambra State Nigeria Journal of Mycotoxicology 2: 22-27

22. Atehnkeng J, Ojiambo PS, Donner M, Ikotun T, Sikora RA, et al. (2008) Distribution and toxigenicity of Aspergillus speciesisolated from maize kernels from three agroecologicalzones in Nigeria. International Journal of Food 7:178-193.

Copyright: $\odot 2017$ Okigbo RN. This is an open-access article distributed under the terms of the Creative Commons Attribution License, which permits unrestricted use, distribution, and reproduction in any medium, provided the original author and source are credited. 